\title{
Controlled Morphology and Mechanical Characterisation of Electrospun Cellulose Acetate Fibre Webs
}

\author{
B. Ghorani, S. J. Russell, and P. Goswami \\ Nonwovens Research Group, Centre for Technical Textiles, University of Leeds, Leeds LS2 9JT, UK \\ Correspondence should be addressed to B. Ghorani; behrooz.ghorani@gmail.com
}

Received 25 January 2013; Revised 13 March 2013; Accepted 14 March 2013

Academic Editor: Wen-Fu Lee

Copyright (C) 2013 B. Ghorani et al. This is an open access article distributed under the Creative Commons Attribution License, which permits unrestricted use, distribution, and reproduction in any medium, provided the original work is properly cited.

\begin{abstract}
The purpose was to interpret the varying morphology of electrospun cellulose acetate (CA) fibres produced from single and binary solvent systems based on solubility parameters to identify processing conditions for the production of defect-free CA fibrous webs by electrospinning. The Hildebrand solubility parameter $(\delta)$ and the radius of the sphere in the Hansen space $\left(D_{(s-p)}\right)$ of acetone, acetic acid, water, $N, N$-dimethylacetamide (DMAc), methanol, and chloroform were examined and discussed for the electrospinning of CA. The Hildebrand solubility parameter $(\delta)$ of acetone and DMAc were found to be within an appropriate range for the dissolution of CA. The suitability of the binary solvent system of acetone: DMAc $(2: 1)$ for the continuous electrospinning of defectfree CA fibres was confirmed. Electrospun webs exhibited improved tensile strength and modulus after heat and alkali treatment (deacetylation) of the as-spun material, and no major fibre morphological degradation occurred during the deacetylation process.
\end{abstract}

\section{Introduction}

Cellulose acetate (CA) fibres and membranes have biomedical applications in ultrafiltration and reverse osmosis $[1,2]$ biosensors and affinity membranes. In webs produced by electrospinning fibre, morphology is an important parameter affecting product performance. The morphology of electrospun fibres is influenced by both the physical and electrical properties of the spinning solution, which is, to a large extent, determined by type of solvent [3]. The selection of solvents for electrospinning and their influence on fibre morphology has been one of the main areas of research in recent years [4]. Wannatong et al. [5] showed that both the density of electrospun webs and the presence of beads can be influenced by the choice of solvent. Uyar and Besenbacher [6] indicated that differences in the dryness of the collected fibres could be attributed to the density and boiling point of the solvent. The collected fibre dryness increased as the density and boiling point of the solvent decreased [5]. Similar work on solvent selection was reported by Jarusuwannapoom et al. [7].

Solvent type can also influence the fibre morphology of the as-spun web. Yang et al. [8] investigated the effects of dichloromethane (MC), ethanol, and N,N-dimethylformamide (DMF) as single and binary solvent systems on the formation of ultrathin uniform poly(vinyl pyrrolidone) (PVP) fibres during electrospinning and noted substantial differences in the collected fibre morphologies ranging from smooth to helical.

Van der Schueren et al. [9] showed that substantial reduction of the cross-sectional area of electrospun fibres could be achieved by selecting a binary rather than a single solvent system. The use of binary solvent systems has been utilised by various researchers to optimise the electrospinning process, for example, achieving a high productivity at the same time as a finer fibre diameter.

Numerous single and mixed solvent systems have been utilised for electrospinning CA [2, 8-12] with one group reporting the development of a ternary system for the preparation of protein $\mathrm{A} / \mathrm{G}$ functionalised CA membranes [13, 14]. Son et al. [10] showed that when acetone was used as a solvent for electrospinning of CA, the tip of the needle was easily blocked because of rapid solvent evaporation indicating that acetone is not an appropriate solvent for continuous electrospinning using the prevailing experimental conditions. However, it was found that ultrafine CA fibres could be obtained using acetone as a solvent when the CA concentration exceeded $17 \%(\mathrm{w} / \mathrm{w})$. Electrospinning continued until the tip of the needle was blocked by evaporation of the acetone. 
Ultrafine CA fibres were successfully produced via electrospinning of CA in a mixed solvent of acetone and water (water content $10-15 \%(\mathrm{w} / \mathrm{w}))$. Ultrafine cellulose fibres could then be regenerated from homogenous deacetylation of CA webs in $\mathrm{KOH} /$ ethanol solution. Electrospinning of a CA solution in acetone and water under acidic conditions produced larger fibres, whereas when the solution was basic, much finer fibres were produced [10]. Han et al. [11] reported that uniform CA fibres could be electrospun at CA concentrations above $17 \%(\mathrm{w} / \mathrm{w})$ in a mixed solvent of acetic acid: water $(75: 25)$. The average diameter of these fibres was $180 \mathrm{~nm}$. Tungprapa et al. [12] showed that smooth fibres were obtained from $16 \%(\mathrm{w} / \mathrm{w})$ CA solutions in $1: 1,2: 1$, and $3: 1$ acetone : DMAc, $14-20 \%(w / w)$ CA solutions in $2: 1$ acetone:DMAc and $8 \%-12 \%(w / w)$ CA solutions in 4:1 methylene chloride (DCM) : methanol. This work also concluded that the most versatile solvent system for electrospinning of CA is a binary system of acetone: $N, N$-dimethylacetamide (DMAc) $(2: 1)$ with $12.5 \%-20 \%$ (w/w) CA concentration [12].

Previous studies on the electrospinning of CA have focused on solvent selection [12, 13], but the identification of suitable solvents has been based on trial and error experimentation, results for similar polymer systems or solubility models limited by the physico-chemical database [14]. The purpose of this research was to interpret the varying morphology of the CA electrospun cellulose fibres in single and binary solvent systems based on the solubility parameters. This enabled suitable solvent systems and optimum processing conditions to be identified as well as the production of defect-free cellulose acetate (CA) fibrous webs by electrospinning. Previously, researchers have investigated changes in tensile properties as a result of deacetylation $[13,15]$. Ma et al. [13] demonstrated the feasibility of applying cellulose fibre membrane prepared by electrospinning as affinity membranes. The influence of heat treatment (post fibre formation) on the mechanical properties of the electrospun CA fibre webs was explored as means of maximising their strength [13]. A similar approach was attempted in the present study based on a previously reported method $[13,15]$.

\section{Material and Methods}

2.1. Materials. Cellulose acetate (Acetyl content, 39.8\% (w/w), $M_{w} 30,000 \mathrm{Da}$ ), acetone, acetic acid, N,N-dimethylacetamide, methanol, chloroform, and sodium hydroxide, was purchased from Sigma-Aldrich (UK) and used without any further purification.

2.2. Sample Preparation. To prepare spinning solutions, single and binary solvent systems were evaluated as follows: (1) Single-acetone, DMAc, acetic acid, chloroform, and methanol; (2) Binary-acetone: distilled water, acetic acid : distilled water, acetic acid : acetone, acetic acid:DMAc, DMAc:acetone, methanol:distilled water, acetone:methanol, and chloroform : methanol. Solutions were prepared by constant stirring at room temperature $\left(25 \pm 5^{\circ} \mathrm{C}\right)$. The CA concentration in the spinning solutions was fixed at a concentration of $15 \%(\mathrm{w} / \mathrm{v})$. This concentration was selected based on previous studies to establish the most suitable solvent systems $[12,15]$. The suitability of each system was assessed in terms of the freedom from precipitation during preparation of the spinning solution and the spinnability of the resulting polymer solution. Spinnability in this context was assessed in terms of freedom from needle blockages, consistency of fibre morphology, and freedom from bead and spindle defects in the web. Clear spinning solutions were obtained after $24 \mathrm{~h}$.

2.3. Electrospinning. Electrospinning of the CA polymer solutions was performed in horizontal alignment at an applied voltage of $20-25 \mathrm{kV}$ and a tip-to-collector distance of $100 \mathrm{~mm}$. The syringe pump feed rate was 0.002 to $0.02 \mathrm{~mL} \mathrm{~min}^{-1}$. A copper electrode supplying the current and voltage was attached to the syringe needle at its base. Electrospinning was performed inside a fume cupboard and was carried out for $60 \mathrm{~min}$ at room temperature. Webs were collected on a square aluminium foil. The single and binary solvent systems were prepared at a fixed CA concentration of $15 \%(\mathrm{w} / \mathrm{v})$ based on the findings of previous studies $[12,15]$. Preliminary work indicated that no fibres could be successfully spun with a CA concentration of less than $13 \%(\mathrm{w} / \mathrm{v})$. The presence of hydroxyl and acetyl groups in CA gives rise to strong intra- and intermolecular interactions, predominately $\mathrm{H}$-bonding. Intermolecular $\mathrm{H}$-bonding results in bridging the adjacent CA structural entities [16]. With concentrations less than $13 \%(\mathrm{w} / \mathrm{v})$, it is proposed that the interactions between adjacent CA molecules (intermolecular $\mathrm{H}$-bonding) are not strong enough for fibre formation that is, the critical chain entanglement concentration for fibre formation was not reached. Precipitation of CA occurred in the binary solvent systems of acetone: water $(4: 1)$, methanol: water $(4: 1)$, and methanol : acetone $(3: 2,4: 1)$ even at a low CA concentration of $10 \%(\mathrm{w} / \mathrm{v})$. A summary of the solvent systems and electrospinning conditions utilised is given in Table 1 . The effects of each solvent on the electrospinnability of the CA spinning solutions and the morphological appearance of the asspun CA fibres were investigated to determine the optimum solvent system for electrospinning of CA.

2.4. Scanning Electron Microscopy (SEM). Prior to SEM imaging (Philips XL30-ESEM), all the samples were cut into small sizes (stubs $12.7 \mathrm{~mm}$ diameter) and were sputter coated (EMscope Biorad SC500) with a gold and platinum mixture in a vacuum. SEM images were taken at different magnifications: high (scale bar $=10 \mu \mathrm{m}$ ), medium (scale bar $=25$ and $50 \mu \mathrm{m}$ ), and low (scale bar $=100 \mu \mathrm{m}$ ) for all samples. Fibre morphology was determined directly from multiple SEM images of the same sample to determine a representative view.

\subsection{Attenuated Total Reflectance Fourier-Transform Infra-} Red (ATR-FTIR) Spectroscopy. The Perkin-Elmer Spectrum $B X$ spectrophotometer with diamond ATR attachment was used in this study (ATR-FTIR) to measure the pre- and postneutralised fibrous webs. Scanning was conducted from 4000 to $600 \mathrm{~cm}^{-1}$ with a resolution of $4 \mathrm{~cm}^{-1}$ and a scanning interval of $2 \mathrm{~cm}^{-1}$ with 64 repetitious scans averaged per sample.

2.6. Tensile Strength Testing. Tensile testing of electrospun webs was conducted using an Instron 5544 single column 
TABLE 1: Experimental conditions: combinations of solvent systems, polymer concentration, and spinning solution flow rate and voltage.

\begin{tabular}{|c|c|c|c|c|c|}
\hline Solvent & $\begin{array}{l}\text { Ratio } \\
(\mathrm{v} / \mathrm{v})\end{array}$ & $\begin{array}{c}\text { Polymer } \\
\text { concentration \% } \\
(\mathrm{w} / \mathrm{v})\end{array}$ & $\begin{array}{c}\text { Flow rate } \\
\left(\mathrm{mL} \min ^{-1}\right)\end{array}$ & $\begin{array}{c}\text { Voltage } \\
(\mathrm{kV})\end{array}$ & As-spun fibres \\
\hline Acetone & - & 15 & 0.02 & $20-25$ & Few ribbon-like fibres \\
\hline DMAc & - & 15 & 0.02 & $20-25$ & Only beads \\
\hline Acetic acid & - & 15 & 0.02 & $20-25$ & No production \\
\hline Chloroform & - & 15 & 0.02 & $20-25$ & Only beads \\
\hline Methanol & - & 15 & 0.02 & $20-25$ & Only beads \\
\hline Acetone: water & $17: 3$ & 15 & 0.02 & $20-25$ & No production \\
\hline Acetone: water & $4: 1$ & 10 & - & - & Precipitation \\
\hline Acetic acid: water & $3: 1$ & 15 & 0.004 & $20-25$ & Large beads \\
\hline Acetic acid: acetone & $3: 1$ & 15 & 0.004 & $20-25$ & Few fibres and large beads \\
\hline Acetic acid: DMAc & $3: 1$ & 15 & 0.004 & $20-25$ & Large beads \\
\hline DMAc: acetone & $2: 1$ & 15 & 0.004 & $20-25$ & Large beads \\
\hline Methanol: water & $4: 1$ & 10 & - & - & Precipitation \\
\hline Methanol: acetone & $3: 2$ and $4: 1$ & 10 & - & - & Precipitation \\
\hline Acetone: methanol & $3: 2$ and $4: 1$ & 15 & 0.004 & $20-25$ & Fibres and small beads \\
\hline Chloroform : methanol & $4: 1$ & 15 & 0.004 & $20-25$ & Some ribbon-like fibres \\
\hline \multirow[t]{3}{*}{ Acetone: DMAc } & $2: 1$ & 15 & 0.004 & $20-25$ & Fibres and small beads \\
\hline & & 20 & 0.004 & $20-25$ & Fibres and small beads \\
\hline & & 25 & 0.002 & $20-25$ & Fibres free of beads \\
\hline
\end{tabular}

system with the Merlin materials testing software. Samples of $5 \mathrm{~mm} \times 20 \mathrm{~mm}$ were measured using a gauge length of $20 \mathrm{~mm}$. The rate of extension was $10 \mathrm{~mm} \mathrm{~min}^{-1}$. Each measurement was replicated three times per sample.

\section{Results and Discussion}

The solubility characteristics of the polymer are of fundamental importance in the process of selecting the suitable solvent systems for electrospinning. Table 1 summarises the solvent systems that were selected based on previous studies [10$12,15]$ and evaluation of the solubility behaviour following the Hansen theory of solubility $[14,17]$. The total solubility parameter $\left(\delta_{t}\right)$ is a numerical value that demonstrates the relative solvency behaviour of a specific solvent. The concept that solubility is related to the internal energy of solvents and solutes was first introduced by Hildebrand as the square root of the cohesive energy density (CED) of the material. The Hansen parameters extended the concept that the total cohesive term and thus the total solubility parameters $\left(\delta_{t}\right)$ of the total Hildebrand value may be divided into: dispersion component $\left(\delta_{d}\right)$, polar component $\left(\delta_{p}\right)$ and hydrogen bonding component $\left(\delta_{h}\right)$. The equation is as follow [17]:

$$
\delta_{t}=\sqrt{\delta_{d}^{2}+\delta_{p}^{2}+\delta_{h}^{2}} .
$$

The SI unit of all the Hansen parameters is $\mathrm{MPa}^{1 / 2}$. Values of $\delta_{d}, \delta_{p}$, and $\delta_{h}$ at room temperature for a variety of CA solvents are given in Table $2[14,18]$. According to Hansen, an approximately spherical area of solubility may be constructed in a three-dimensional coordinate system of $\delta_{d}, \delta_{p}$, and $\delta_{h}$. The radius of that sphere is called the interaction radius $(R)$, and the value of $R$ for CA is $12.40 \mathrm{MPa}^{1 / 2}$ [18]. A polymer is probably soluble in a solvent if the distance between the solvent and the centre of the polymer solubility sphere $\left(D_{(s-p)}\right)$ is less than the radius of interaction for the polymer $\left(D_{(s-p)}<\right.$ R) $[14,17,18]$. Accordingly, acetone, DMAc, acetic acid, chloroform, and partly methanol would be expected to dissolve CA (Table 2$)$. The Hansen sphere $\left(D_{(s-p)}\right)$ of water and methanol are 32.47 and $12.35 \mathrm{MPa}^{1 / 2}$, respectively, which is not within an appropriate range for the dissolution of CA, particularly for water (Table 2). Therefore, the preparation of CA solutions in the binary solvent systems of acetone : water (4:1), methanol: water $(4: 1)$, and methanol:acetone $(3: 2$ and $4: 1)$ were hampered due to precipitation of polymer during the stirring process (Table 1).

Table 3 summarises the boiling points, viscosity, surface tension, and the Hildebrand and the Flory-Huggins parameters for each solvent type $[15,19,20]$. The Hildebrand solubility parameter $(\delta)$ indicates the degree of interaction between materials and can be a good predictor of solubility, particularly for nonpolar polymer materials [15]. The Hildebrand solubility parameter $(\delta)$ is derived from the cohesive energy density of the solvent, which in turn is derived from the heat of vaporisation [21]. CA is soluble in solvents when the Hildebrand solubility parameters $(\delta)$ lie between 9.5 and $12.5\left(\mathrm{cal} \mathrm{cm}^{-3}\right)^{1 / 2}[15]$.

The Hildebrand solubility parameters of acetic acid and chloroform are 13.1 and $9.21\left(\mathrm{cal} \mathrm{cm}^{-3}\right)^{1 / 2}$, respectively, which is not within an appropriate range for the dissolution of CA (Table 3). However, Table 2 shows the Hansen sphere $\left(D_{(s-p)}\right)$ of acetic acid and chloroform are 2.68 and $8.87 \mathrm{MPa}^{1 / 2}$, respectively, which is less than the radius of interaction $(R)$ 
TABLE 2: Total solubility parameters $\left(\delta_{t}\right)$ of various solvents and cellulose acetate $[14,18]$.

\begin{tabular}{lcccccc}
\hline \multirow{2}{*}{ Liquid } & \multicolumn{5}{c}{ Solubility parameter $\left(\mathrm{MPa}^{1 / 2}\right)$} \\
& $\delta_{t}$ & $\delta_{d}$ & $\delta_{p}$ & $\delta_{h}$ & ${ }^{*} D_{(s-p)}$ & $R$ \\
\hline Acetone (AC) & 19.93 & 15.50 & 10.40 & 7.00 & 5.39 & \\
Dimethylacetamide & 22.77 & 16.80 & 11.50 & 10.20 & 5.88 & \\
(DMAc) & 21.36 & 14.5 & 8.0 & 13.5 & 2.68 & \\
Acetic acid & 29.60 & 15.10 & 12.30 & 22.30 & 12.35 & \\
Methanol & 19 & 17.80 & 3.10 & 5.70 & 8.87 & \\
Chloroform & 47.83 & 15.60 & 16.0 & 42.3 & 32.47 & \\
Water & 19.89 & 14.90 & 7.10 & 11.10 & - & 12.40 \\
Celluloce acetate (CA) & & & & &
\end{tabular}

${ }^{*} D_{(s-p)}=\left[4\left(\delta_{d S}-\delta_{d P}\right)^{2}+\left(\delta_{p S}-\delta_{p P}\right)^{2}+\left(\delta_{h S}-\delta_{h P}\right)^{2}\right]^{1 / 2}$

$\delta_{x s}=$ The Hansen component parameter for the solvent.

$\delta_{x p}=$ The Hansen component parameter for the polymer.

of CA and would be expected to dissolve the CA. This may be attributed to the fact that the predictions using the Hildebrand solubility parameters are made with the absence of any specific interactions, especially hydrogen bonds. [21]. Therefore, all experiments were conducted using acetone, acetic acid, DMAc, chloroform, and methanol. Other important considerations are the boiling temperature $\left({ }^{\circ} \mathrm{C}\right)$, viscosity $(\eta)$, and surface tension $(\gamma)$ which were also taken into account (Table 3 ) in the selection of an appropriate solvent because they also affect the prospect of continuous electrospinning of ultrafine and uniform CA fibres. Additionally, binary solvents were studied since they could also potentially provide solvent systems with properties that were suitable for continuous, blockage-free electrospinning.

A summary of the spinning performance of each polymer solution is given in Table 1, which summarises the formation of continuous fibres or beads as a function of processing conditions. The solubility of CA in the selected solvent does not necessarily mean that fibres could be continuously produced during electrospinning; in many cases, beads were produced, and, in others, continuous spinning was interrupted by the volatility of the solvent in the polymer solution. In the preparation of the spinning solutions, different polymer concentrations were examined; however, except for the binary solvent systems containing acetone:DMAc, none of the solutions successfully produced substantially bead-free fibres (Table 1). Fibrous webs could not be obtained using a CA concentration of less than $13 \%(w / v)$. Similarly, spinnability issues were encountered due to high viscosity at polymer concentrations greater than $18 \%-20 \%$ (w/v) using single solvent systems. Specifically, continuous electrospinning of CA from solutions containing acetone, methanol, and chloroform alone was impeded due to their volatility and low boiling point (Table 3); beads were obtained on the screen collector for single solvent systems of chloroform and methanol (Figures 1(a) and 1(b)) [10, 15]. Acetic acid as a solvent did not enable production of a fibrous web, which is in agreement with the reported literature [11]. Liu and Hsieh [15] first reported that CA solutions in acetic acid could not be continuously electrospun, which may be attributable to the relatively low dielectric constant of acetic acid resulting in unstable electrospinning conditions [9].

Satisfactory spinning conditions could not be established for acetone: water in ratios of $17: 3(85: 15)$ under the given experimental conditions $[10,22]$. The solubility of CA in acetone:water is affected by the relative concentration of solvents such that the spinning solution could not be satisfactorily produced in a ratio of $4: 1(80: 20)$ due to the precipitation of CA (Table 1). Reducing the concentration to $10 \%(\mathrm{w} / \mathrm{v})$ did not improve the results. The poor performance of this particular solvent system may be explained in terms of the Hildebrand solubility $(\delta)$ and the Flory-Huggins $(\chi)$ parameters of water (Table 3 ). The Flory-Huggins parameter $(\chi)$ characterises the polymer-solvent interaction, wherein a smaller value of $\chi$ indicates a more thermodynamically compatible interaction between the solvent and the polymer [15]. Therefore, among the six solvents examined, DMAc was expected to be the most thermodynamically compatible solvent for CA, followed by chloroform, acetic acid, acetone, water, and methanol. The Hildebrand solubility and the Hansen sphere $\left(D_{(s-p)}\right)$ for water are also $23.5\left(\mathrm{cal} / \mathrm{cm}^{-3}\right)^{1 / 2}[19]$ and $32.47 \mathrm{MPa}^{1 / 2}$, respectively (Table 2 ), which is not within an appropriate range for the dissolution of CA. Therefore, it was observed that there was greater precipitation of CA as the amount of water increased in the binary solution of acetone and water. Incorporation of water also decreased the overall evaporation rate during electrospinning [23]. In the present study, satisfactory spinning conditions could not be established with 3:1 acetic acid: water as a solvent either, using the given experimental conditions because continuous electrospinning was hampered (Figures 1(c) and 1(d)).

Similarly, a satisfactory spinning solution could not be established for methanol : water $(4: 1)$. The poor performance of this binary solvent system is attributed to the high Hildebrand solubility $(\delta)$ and Hansen sphere $\left(D_{(s-p)}\right)$ for water and methanol which is not within an appropriate range for the dissolution of CA (Tables 2 and 3). The Flory-Huggins $(\chi)$ parameter of methanol (1.87) is also the highest amongst the solvents used for this study followed by water (1.4) (Table 3) suggesting these two solvents are the least thermodynamically compatible for dissolving CA. The precipitation of cellulose acetate in the binary solvent systems of acetone: water $(4: 1)$, methanol: water $(4: 1)$, and methanol: acetone $(4: 1,3: 2)$ therefore prevented spinning trials using these particular solvent systems.

Tubular, collapsed ribbon, tape, branched, and various other morphological forms are frequently observed in electrospun materials depending on solvent properties, spinning solution rheology and process conditions [24]. Ribbon-like fibres were observed in the webs produced from acetone with a relatively large ribbon width of $28 \mu \mathrm{m}$ (range of $10.28-$ $61.13 \mu \mathrm{m}$ ) (Figure 2(a)). When a highly volatile solvent system is used for electrospinning, the tubular fibre skin of the jet collapses due to a rapid vaporisation of the solvent from within the fibre $[24,25]$. Koombhongse et al. [24] reported that irregular shaped beads can be observed since the skin on the bead also collapses due to the rapid removal of solvent from the interior. The rapid rate of evaporation of acetone 
TABLE 3: Physical properties of solvents [15, 19, 20, 31].

\begin{tabular}{|c|c|c|c|c|c|}
\hline Solvent & $\begin{array}{c}\text { Boiling } \\
\text { temperature } \\
\left({ }^{\circ} \mathrm{C}\right)\end{array}$ & $\begin{array}{c}\text { Viscosity }(\eta) \mathrm{cP} \text { at } \\
20^{\circ} \mathrm{C}\end{array}$ & $\begin{array}{c}\text { The Flory-Huggins } \\
\text { parameter } \\
(\chi) \text { at } 25^{\circ} \mathrm{C}\end{array}$ & $\begin{array}{l}\text { Hildebrand } \\
\text { Solubility } \\
\text { parameter }(\delta) \\
\left(\mathrm{cal} / \mathrm{cm}^{3}\right)^{1 / 2}\end{array}$ & $\begin{array}{c}\text { Surface tension }(\gamma) \\
\left(\text { dyne } \mathrm{cm}^{-1}\right) \text { at } \\
20^{\circ} \mathrm{C}\end{array}$ \\
\hline Water & 100 & 1 & 1.4 & 23.5 & 72.8 \\
\hline Acetone & 56.29 & 0.36 & 0.48 & 9.77 & 23.32 \\
\hline DMAc & 164 & 2.14 & 0.28 & 11.1 & 32.43 \\
\hline Acetic acid & 117.9 & 1.31 & 0.41 & 13.1 & 27.6 \\
\hline Chloroform & 61.2 & 0.56 & 0.34 & 9.21 & 27.50 \\
\hline Methanol & 65 & 0.59 & 1.87 & 14.3 & 22 \\
\hline
\end{tabular}

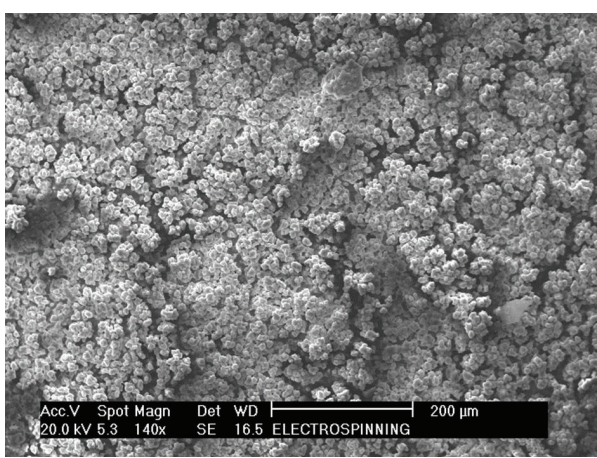

(a)

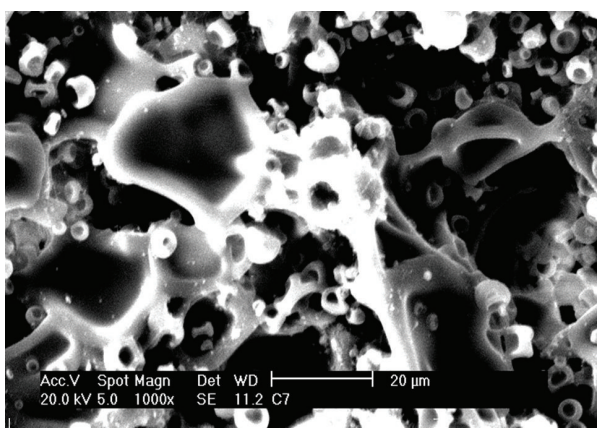

(c)

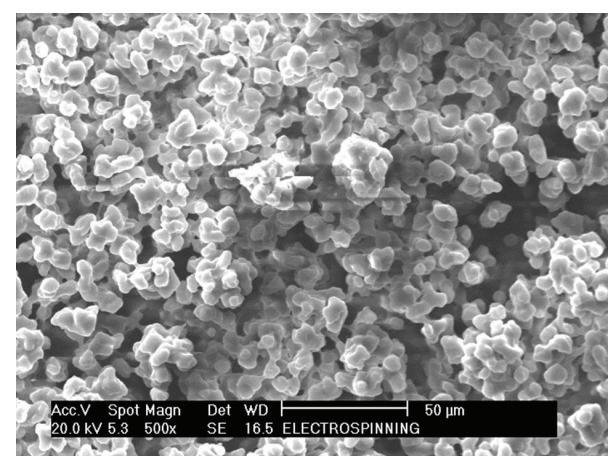

(b)

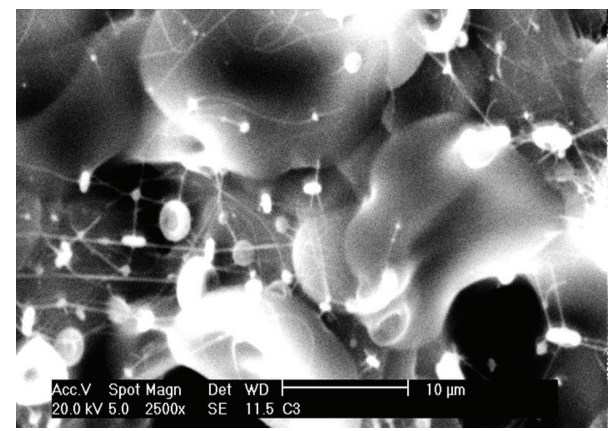

(d)

FIGURE 1: SEM micrographs showing the effect of: (a) chloroform as solvent on resulting CA electrospun fibre morphology, Mag 140x (b) Methanol, Mag 500x, and ((c)-(d)) Acetic acid : water (3:1) Mag 1000x-2500x.

therefore leads to ribbon-like fibres being observed in the asspun web (Figure 2(a)). Moreover, the low boiling point of acetone (lowest amongst of the solvent used in this study) gives rise to needle tip blockage, which hampers continuous electrospinning (Table 3 ).

It was not possible to spin fibres from a CA solution in DMAc under the prevailing experimental conditions. Strong hydrogen bonding between CA and DMAc [26] and the high boiling point of the solvent (Table 3 ) resulted in poor evaporation of DMAc during electrospinning. The evidence of insufficient solvent evaporation may be observed in Figure 2(b). Similarly, a high incidence of bead formation was observed in the webs produced from the binary solvent system of acetic acid : DMAc $(3: 1)$ (Figure 2(c)). This could also be attributed to the high boiling point of the solvents and the strong hydrogen bonding between CA and DMAc which results in insufficient solvent evaporation [27].

CA solutions with concentration of $15 \%(\mathrm{w} / \mathrm{v})$ in the binary solvent system of acetic acid: acetone $(3: 1)$ was also examined. Acetic acid:acetone (3:1) mixtures supported continuous electrospinning and web formation. The resultant fibres, however, contained many large beads on their surface (Figure 2(d)). The average fibre diameter was found to be $12.06 \mu \mathrm{m}$ (range of 11.22-16.78 $\mu \mathrm{m}$ ). Liu and Hsieh [15] indicated that CA solutions produced from acetic acid:DMAc and acetic acid : acetone mixtures could be continuously electrospun, however fibres with a diameter of $1-2 \mu \mathrm{m}$ containing large beads were formed.

For the remaining solvents, acetone: methanol $(3: 2$ and $4: 1)$, chloroform : methanol $(4: 1)$, and acetone : DMAc $(2: 1)$ 


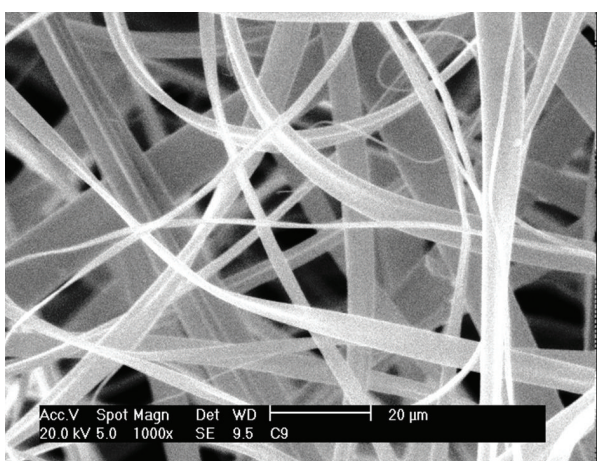

(a)

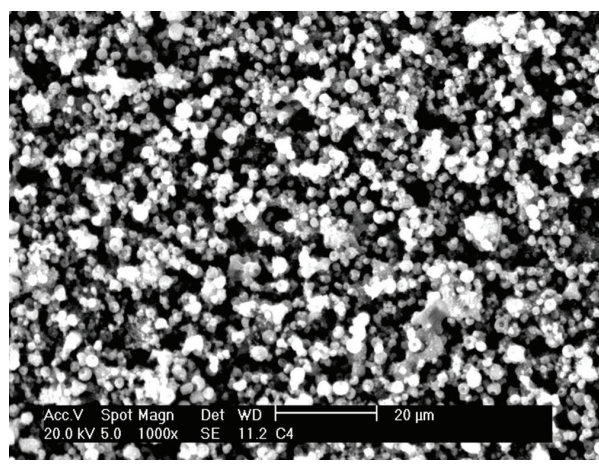

(c)

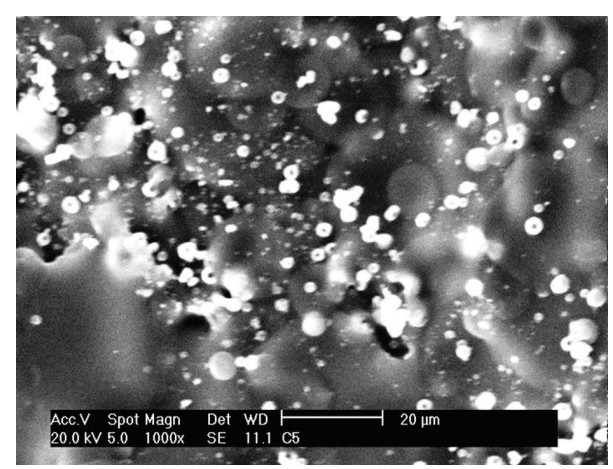

(b)

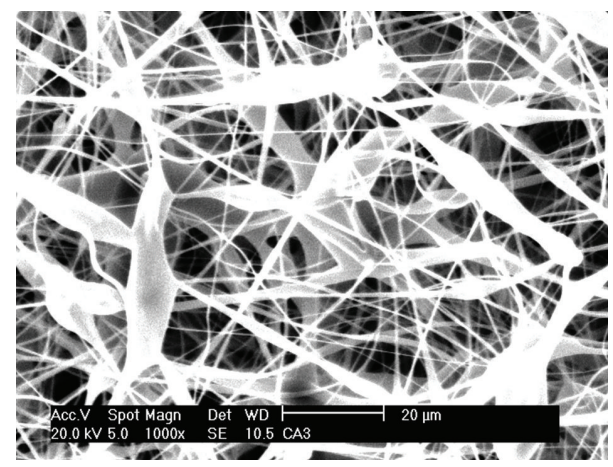

(d)

FIGURE 2: SEM micrographs showing the effect of individual and binary solvent systems on resulting CA electrospun fibre morphology. Mag 1000x-3000x (a) acetone; (b) DMAc; (c) acetic acid: DMAc (3:1), and (d) acetic acid : acetone $(3: 1)$.

fibrous webs were satisfactorily produced on a continuous basis for up to one hour confirming their suitability for continuous web production.

The solubility of CA in a binary solvent of methanol and acetone is affected by the ratio of methanol and acetone in the solution; spinning solutions could not be satisfactorily produced when the ratios were $3: 2$ and $4: 1$ methanol: acetone due to precipitation of CA. However, by increasing the amount of acetone in this binary solution (acetone : methanol $3: 2$ and $4: 1$ ), clear spinning solutions were produced; spinning from this solution resulted in fibrous webs containing small beads with fibre diameters ranging between $436 \mathrm{~nm}$ and $1.01 \mu \mathrm{m}$. Typical web structures produced from each solvent system are shown in Figures 3(a) and 3(b). The mean fibre diameter, fibre morphology, and the prevalence of bead formation were found to depend upon the solvent system. The mean fibre diameter of the webs produced from the $4: 1$ acetone : methanol binary solution was $4.35 \pm 0.5 \mu \mathrm{m}$, and from the $3: 2$ acetone: methanol binary solution, it was $1.99 \pm$ $0.5 \mu \mathrm{m}$. Morphologically, smooth fibres were observed in all webs.

Fibres produced from the binary solution of chloroform:methanol $(4: 1)$ were irregular in morphology and ribbon-like fibre structures were present as indicated in Figures 3(c) and 3(d). The presence of the ribbon-like fibres could be attributable to the rapid evaporation of chloroform from the polymer surfaces. The mean fibre diameter of the CA fibres produced from this spinning solution was $1 \pm 0.5 \mu \mathrm{m}$.
It has previously been reported that increasing the methanol content in solvent systems can contribute to the formation of both beaded and smooth fibres [28].

Table 3 demonstrates that DMAc and acetone possess the two extremes of solvent properties. To achieve intermediate surface tensions and viscosities, CA was dissolved in a binary solvent system of acetone: DMAc in different ratios. Electrospinning of CA in DMAc:acetone $(2: 1)$ at any concentration generated beads rather than fibres (Figure 4(a)), similar to the use of DMAc alone. Liu and Hsieh [15] also showed that DMAc: acetone $(2: 1)$ is not a suitable solvent for the electrospinning of CA due to its high surface tension. However, increasing the fraction of acetone to DMAc $(2: 1)$ improved spinning stability and produced substantiality smaller beads. Fibres of $140 \mathrm{~nm}-582 \mathrm{~nm}$ diameter (mean $=264 \pm 0.5 \mathrm{~nm}$ ) were produced as shown in Figure $4(\mathrm{~b})$ at a polymer concentration of CA $15 \%(\mathrm{w} / \mathrm{v})$.

The morphology of the electrospun CA fibres produced using the binary solution of acetone : DMAc $(2: 1)$ was found to vary with the concentration of the $\mathrm{CA}$ in the solution. The SEM images of fibres produced from 15\% (w/v) and $20 \%$ (w/v) CA concentrations are shown in Figure 5. Spherical bead-like particles were observed for CA electrospun fibres produced from $15 \%(\mathrm{w} / \mathrm{v}) \mathrm{CA}$ in acetone:DMAc $(2: 1)$ solution (Figures 5(a) and 5(b)). The morphology of electrospun webs were improved with an increase in the CA concentration to 20\% (w/v) (Figures 5(c) and 5(d)). The size and number of beads decreased and the fibre diameter 


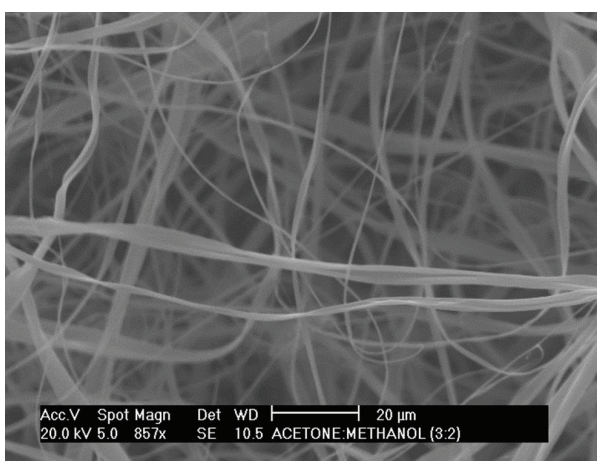

(a)

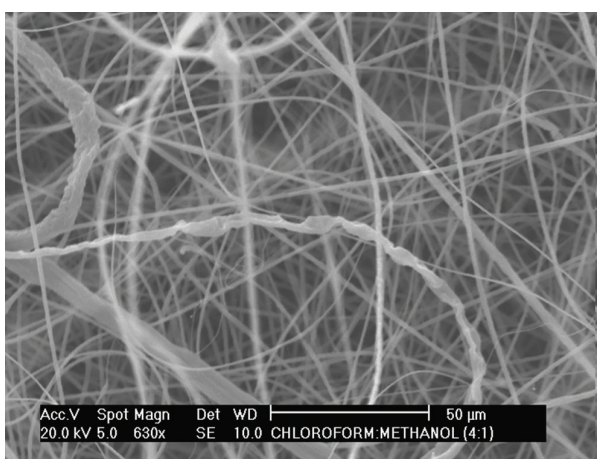

(c)

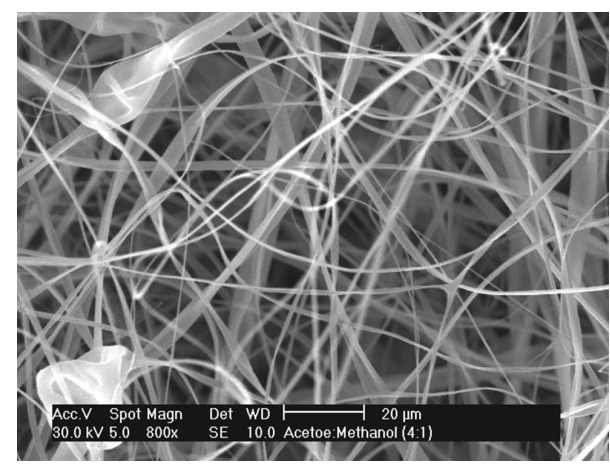

(b)

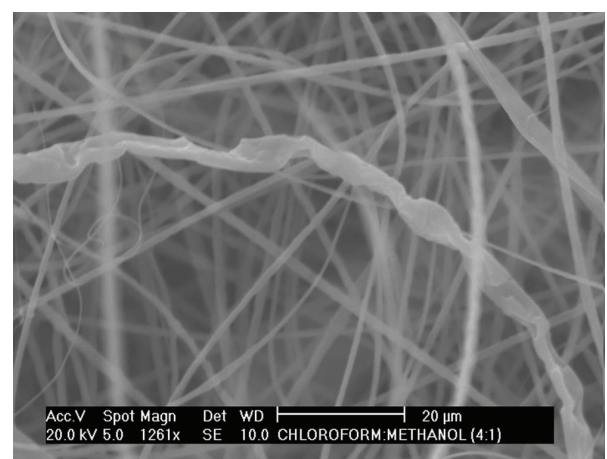

(d)

FIGURE 3: SEM micrographs showing the effect of binary solvent systems on web structure and CA electrospun fibre morphology. Mag 630x1260x-electrospinning solvents: (a) acetone: methanol (3:2); (b) acetone: methanol (4:1); (c) chloroform : methanol (4:1); (d) ribbon-like structure in an electrospun CA fibre produced from the Chloroform : methanol $(4: 1)$ solvent.

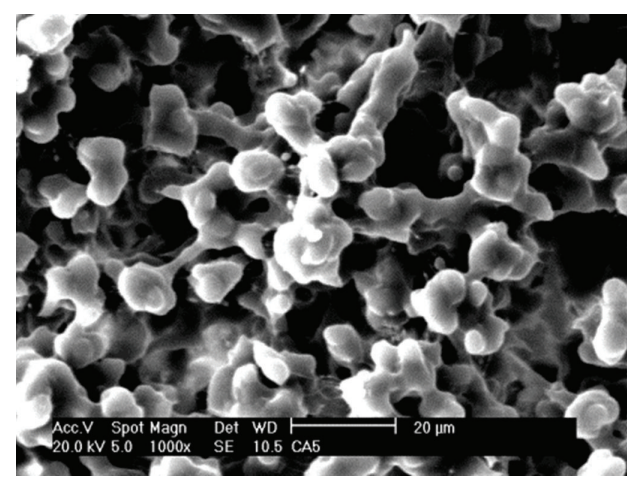

(a)

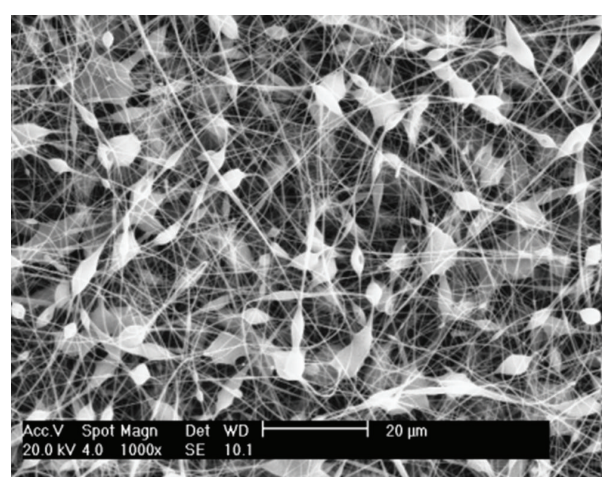

(b)

FIGURE 4: SEM micrographs showing the effect of binary solvent systems on resulting CA electrospun fibre morphology and web structure at a polymer concentration of $15 \%(w / v)$. Mag 300x: (a) DMAc: acetone (2:1) large beads, (b) acetone: DMAc (2:1) fibres and small beads.

increased as the CA concentration increased from $15 \%$ to $25 \%(\mathrm{w} / \mathrm{v})$. The range of fibre diameters of beaded-fibres electrospun from a $15 \%(\mathrm{w} / \mathrm{v})$ CA solution under different electrospinning conditions was around $140 \mathrm{~nm}-582 \mathrm{~nm}$. At CA concentrations of $20 \%(\mathrm{w} / \mathrm{v})$ and $25 \%(\mathrm{w} / \mathrm{v})$, continuous and uniform electrospun fibres were generated with fibre diameters of $192-957 \mathrm{~nm}($ mean $=395 \pm 0.5 \mathrm{~nm})$ and $318 \mathrm{~nm}-$ $1.80 \mu \mathrm{m}$ (mean $=635 \pm 0.5 \mathrm{~nm}$ ), respectively. The results clearly indicate that electrospun fibre diameter increased by increasing the CA concentration. These results confirm that the most versatile solvent system for electrospinning of
CA is a binary system of acetone:DMAc (2:1) (Figure 5). Further experiments revealed that optimum conditions for the production of cellulose acetate (CA) in a binary solvent system of acetone:DMAc $(2: 1)$ can be identified as a CA polymer concentration of $25 \%(\mathrm{w} / \mathrm{v})$, voltage $25 \mathrm{kV}$ and a flow rate of $0.002\left(\mathrm{~mL} \mathrm{~min}^{-1}\right)$ (Figure 6).

3.1. Effect of Deacetylation of Ultrafine Cellulose Acetate on Fibre Properties. Previously researchers have investigated changes in tensile properties as a result of deacetylation [13]. In this study, the influence of heat treatment (post web 


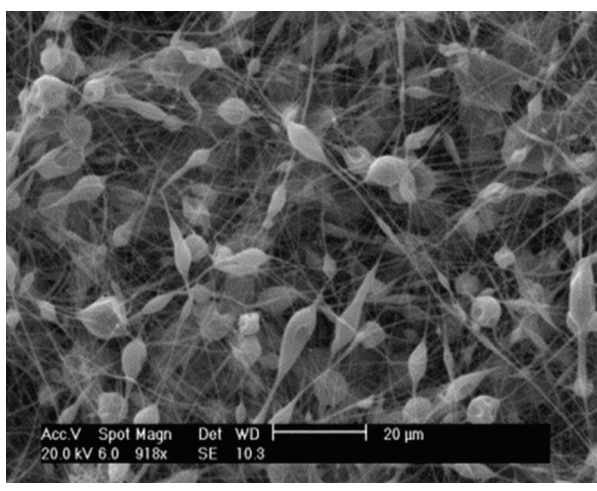

(a)

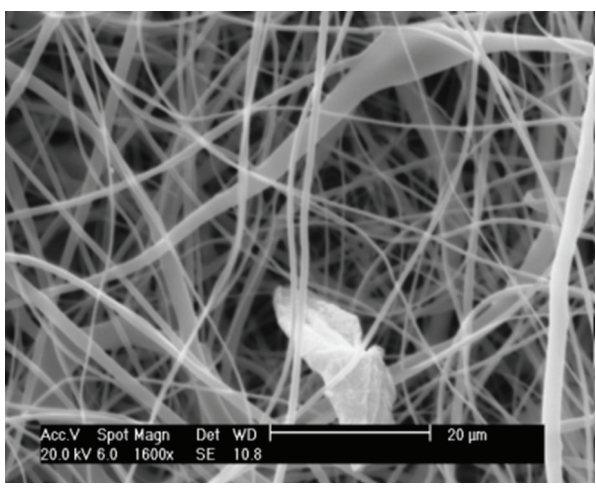

(c)

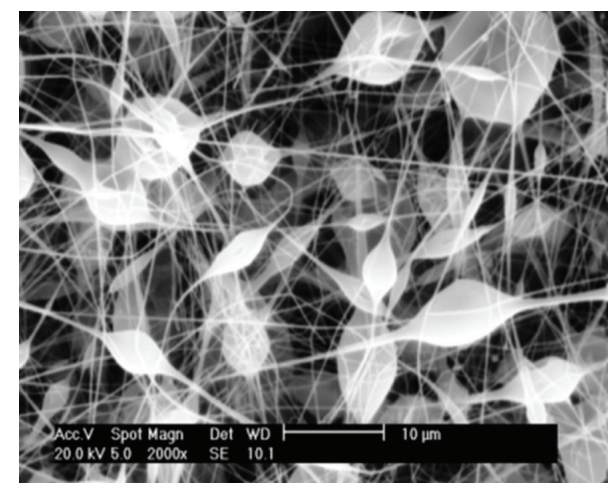

(b)

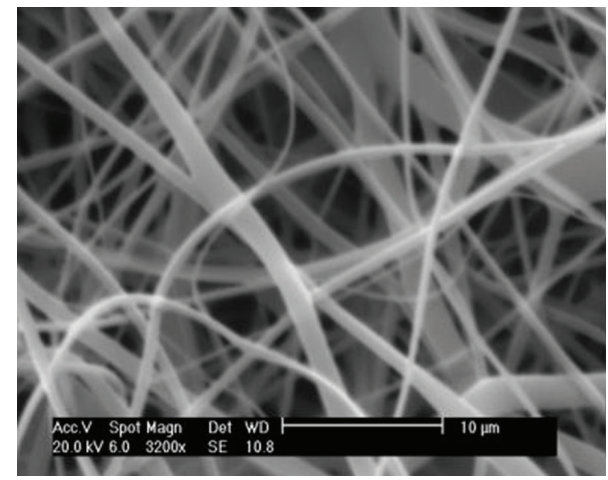

(d)

FIGURE 5: SEM micrographs of CA webs produced from binary mixed solvent systems: acetone: DMAc $(2: 1)$ at polymer concentrations: $((\mathrm{a})-(\mathrm{b})) 15 \%(\mathrm{w} / \mathrm{v})$ mean fibre diameter $=264 \pm 0.5 \mathrm{~nm}$ :, ((c)-(d)): $20 \%(\mathrm{w} / \mathrm{v})$ mean fibre diameter $=395 \pm 0.5 \mathrm{~nm}$.

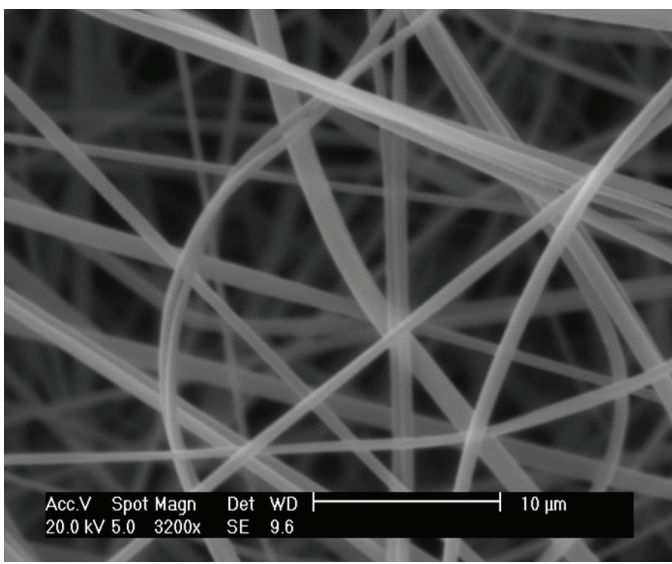

(a)

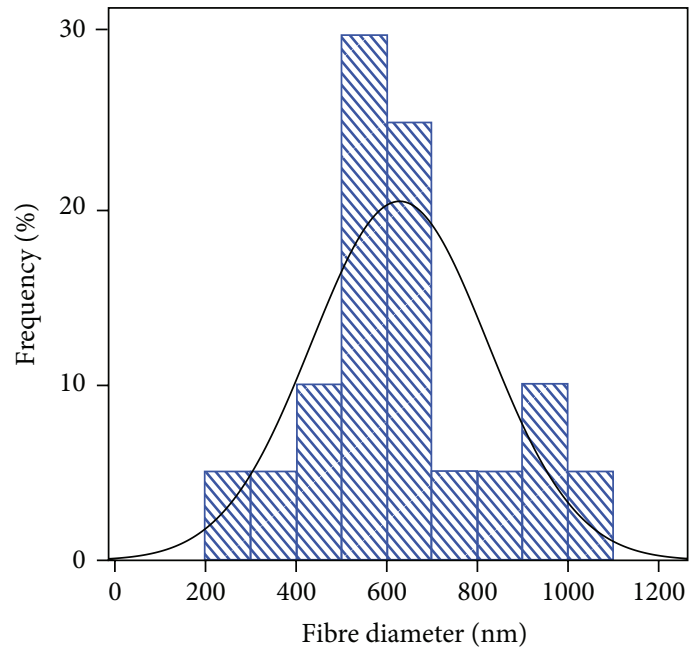

(b)

FIGURE 6: SEM micrograph of CA web produced from the binary solvent system acetone : DMAc at a polymer concentration of $25 \%$ (w/v). The operating voltage was $25 \mathrm{kV}$ and the flow rate $0.002\left(\mathrm{~mL} \mathrm{~min}^{-1}\right)$ (b) Fibre diameter distribution obtained using optimum spinning conditions.

formation) on the mechanical properties of the electrospun CA fibre webs $(25 \% \mathrm{w} / \mathrm{v}$ in a binary solvent system of acetone:DMAc $(2: 1)$, voltage $25 \mathrm{kV}$ and a flow rate of $0.002 \mathrm{~mL} \mathrm{~min}^{-1}$ ) was explored as a means of maximising their strength.
3.1.1. Heat and Alkaline Treatment of the Cellulose Fibres. Electrospun CA webs were carefully removed from the aluminum foil and then placed into an oven at $208^{\circ} \mathrm{C}$ for 1 hour. A temperature of $208^{\circ} \mathrm{C}$ was selected because it is known that the glass transition temperature $\left(T_{g}\right)$ of CA is $198-205^{\circ} \mathrm{C}$ 


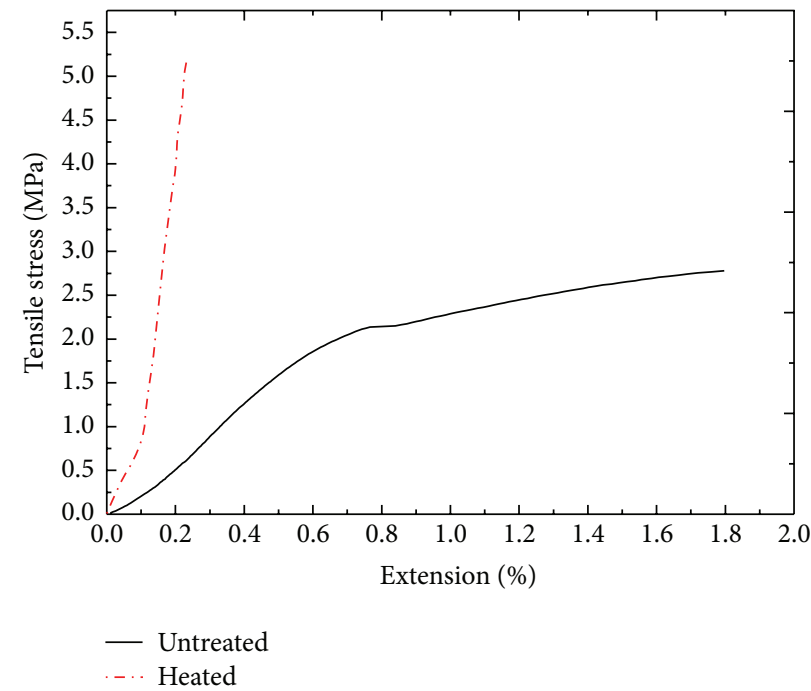

Figure 7: Tensile stress-strain curve of the untreated CA fibre web and the heat-treated CA webs. Cross-head speed was $10 \mathrm{~mm} \mathrm{~min}^{-1}$, web thickness: $150 \mu \mathrm{m}$, sample width: $6.35 \mathrm{~mm}$.

and the melting temperature $\left(T_{m}\right)$ is $224-230^{\circ} \mathrm{C}[13]$. The heat treated CA webs were then immersed in a $4 \mathrm{~g} \mathrm{dm}^{-3}$ $\mathrm{NaOH}$ solution in an ethanol: water (1:4) mixture for $24 \mathrm{hr}$ at room temperature. It has been shown that deacetylation with $\mathrm{NaOH}$ is more efficient and complete in ethanol than under aqueous conditions $[10,29]$. Acetyl groups in the CA molecules could be completely removed via the hydrolysis reaction [30], after deacetylation fibres were rinsed in distilled water and left in desiccators under vacuum until dry.

3.1.2. Tensile Properties. The untreated webs exhibited low tensile strength and high elongation at break compared to the heat treated material. The tensile modulus and tensile strength were improved via the heat treatment process, consistent with previous findings [13]. Figure 7 displays the tensile stress-strain curve of the untreated CA webs compared to the heat-treated CA webs obtained at a cross-head speed of $10 \mathrm{~mm} \mathrm{~min}^{-1}$. The increase in tensile strength can be attributed to cross-linking between the CA fibres after heat treatment leading to interfacial bonding between fibres at the cross-over points as is evident from Figure 8 . As a result, the material's structural integrity and the mechanical strength were dramatically improved [13]. Interestingly, the fibre morphology was not modified by heat treatment and remained intact. All results are in full agreement with previous research reported by $\mathrm{Ma}$ and coworkers [13].

An ATR-FTIR spectrum of the untreated cellulose acetate web is shown in Figure 9(a). The broad absorption band seen at $3478 \mathrm{~cm}^{-1}$ is attributed to $\mathrm{O}-\mathrm{H}$ stretching $[10,13,15]$. The band at $1738 \mathrm{~cm}^{-1}$ is associated with the overlapped ester carbonyls in CA. This peak is a characteristic peak for CA as other bands may also occur in other cellulosic polymers. Figure 9(b) shows changes in the ATR-FTIR spectra of CA fibres after deacetylation for $24 \mathrm{hr}$ (RC web). As can be observed, the characteristic acetyl band for CA at $1738 \mathrm{~cm}^{-1}$ completely disappeared, indicating that the cellulose acetate is converted to regenerated cellulose (Cellulose II). Also, the broad absorption band seen at $3478 \mathrm{~cm}^{-1}$ in Figure 9(a) appears to be larger in Figure 9(b). This suggests the presence of more hydroxyl groups after deacetylation. Interestingly, the alkaline treatment did not result in any major morphological changes in the constituent fibres (Figure 10).

\section{Conclusion}

The aim of this research was to interpret the varying morphology of electrospun cellulose acetate (CA) fibres in single and binary solvent systems based on solubility parameters to identify suitable solvent systems and optimum processing conditions consistent with the production of defect-free CA fibrous webs. In the present study, six solvents, namely, acetone, acetic acid, water, $N, N$-Dimethylacetamide (DMAc), chloroform, and methanol were examined as single and binary solvent systems for the electrospinning of cellulose acetate (CA). The results indicated that fibres could not be continuously produced when acetone, chloroform, and methanol were used as solvents to prepare CA electrospinning solutions because of needle tip blockage as a consequence of their high volatility and low boiling point. Only a few ribbon-like fibres were observed to varying extents in the webs produced from acetone and a relatively large ribbon width was obtained. Similarly, no fibres were obtained from CA solutions comprising acetic acid due to the relatively low dielectric constant of the solvent, which results in unstable electrospinning. The strong hydrogen-bonding interaction between CA and DMAc and also its high boiling point reduces the evaporation rate of DMAc molecules during electrospinning in the short travel distance from the needle tip to the collector.

Based on the Hansen solubility parameters $\left(D_{(s-p)}<\right.$ 12.40), CA is soluble in acetic acid (2.68), acetone (5.39), DMAc (5.88), chloroform (8.87), and methanol (12.35). Similarly, CA is soluble in solvents when the Hildebrand solubility 


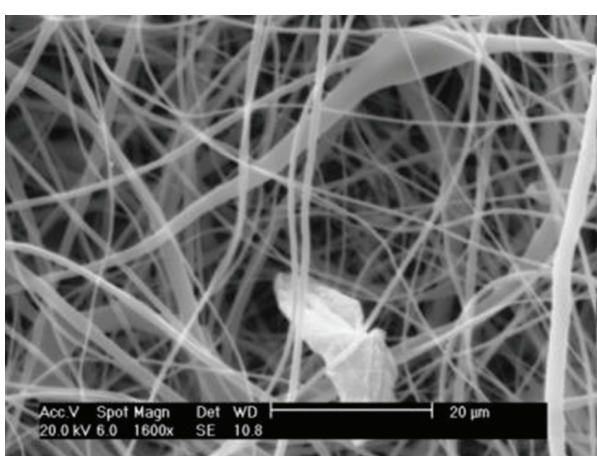

(a)

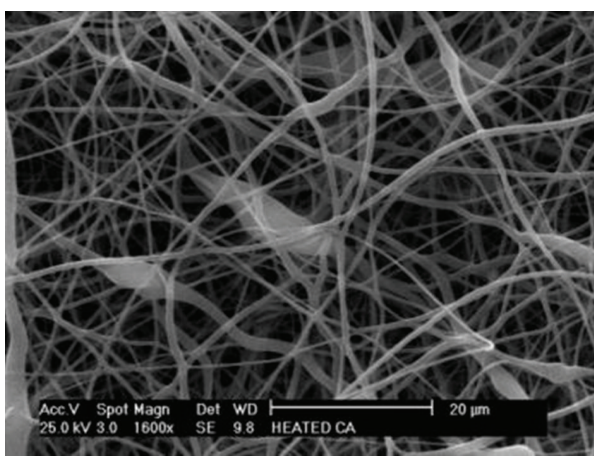

(c)

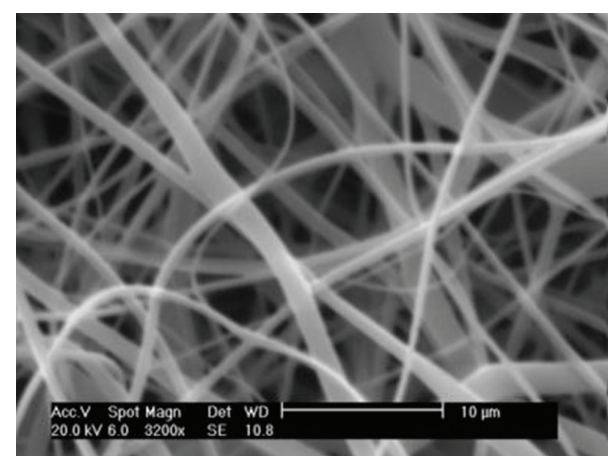

(b)

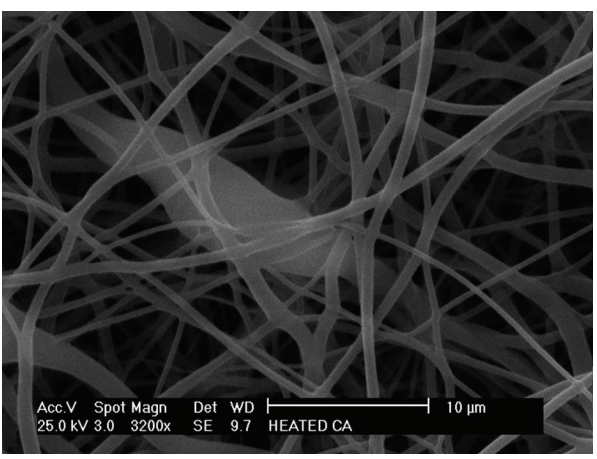

(d)

Figure 8: Selected SEM images of electrospun fibres ((a), (b)) cellulose acetate (25\% w/v) web; ((c), (d)) heat-treated CA web.

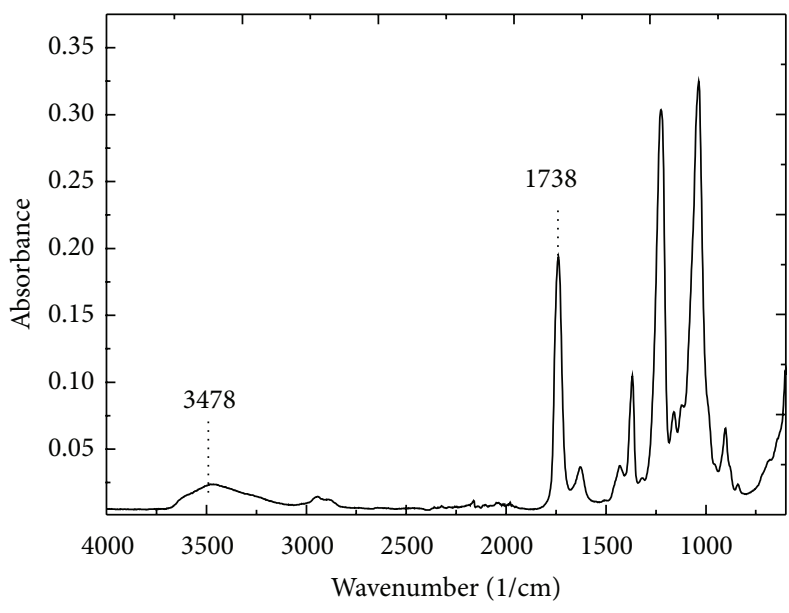

— Untreated CA

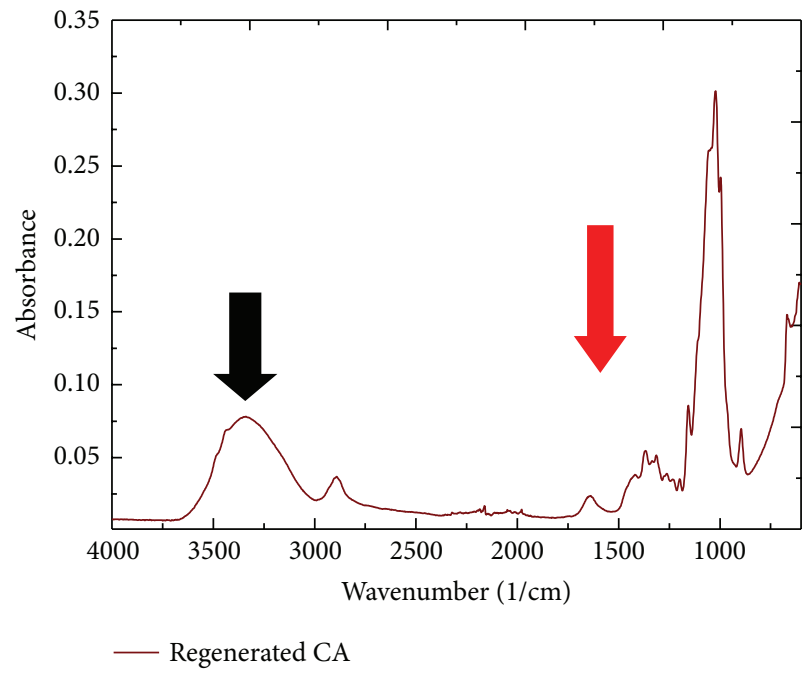

(b)

FIgURE 9: ATR-FTIR spectra of the electrospun CA fibre webs (a) CA web and (b) regenerated Cellulose web.

parameters $(\delta)$ lie between 9.5 and $12.5\left(\mathrm{cal} / \mathrm{cm}^{3}\right)^{1 / 2}$, and therefore, among the six solvents examined, only two solvents meet both solubility criteria : acetone and DMAc with, Hildebrand solubility parameters of 9.77 and $11.1\left(\mathrm{cal} / \mathrm{cm}^{3}\right)^{1 / 2}$, respectively.

A binary solvent system of acetone:DMAc $(2: 1)$ was found to be the most suitable solvent system for continuous electrospinning of CA fibres. The preferred conditions for electrospinning of CA in acetone : DMAc $(2: 1)$ were a polymer concentration of $25 \%(\mathrm{w} / \mathrm{v})$, voltage of $25 \mathrm{kV}$, and flow rate of $0.002\left(\mathrm{~mL} \mathrm{~min}^{-1}\right)$. CA fibres exhibited improved tensile strength and modulus after heat and alkaline treatment (deacetylation) of the as-spun web. No substantial fibre morphological degradation occurred during this process. 


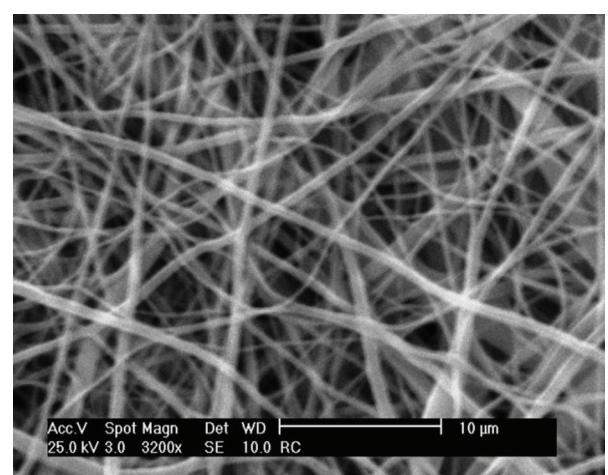

(a)

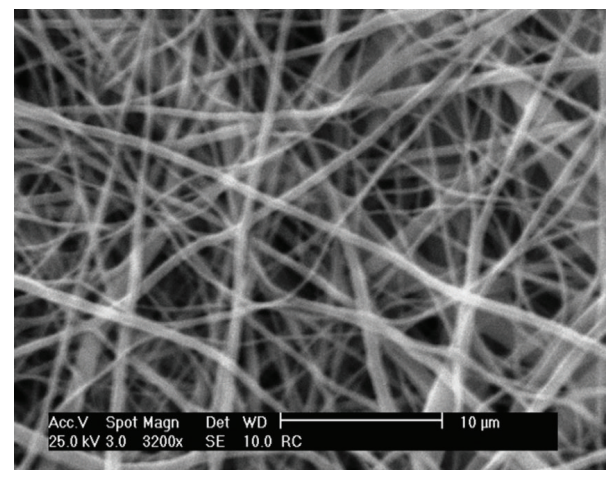

(b)

FIGURE 10: SEM images of the surface of the regenerated cellulose fibres at a polymer concentration of $25 \%(\mathrm{w} / \mathrm{v})$. The operating voltage was $25 \mathrm{kV}$ and the flow rate $0.002\left(\mathrm{~mL} \mathrm{~min}^{-1}\right)$.

\section{References}

[1] A. Idris, K. Y. Lee, and H. K. Hing, "Preparation of cellulose acetate dialysis membrane for separation of bovine serum albumin," Journal of Technology, vol. 42, pp. 35-46, 2005.

[2] Z.-M. Huang, Y. Z. Zhang, M. Kotaki, and S. Ramakrishna, "A review on polymer nanofibers by electrospinning and their applications in nanocomposites," Composites Science and Technology, vol. 63, no. 15, pp. 2223-2253, 2003.

[3] G. Eda, J. Liu, and S. Shivkumar, "Solvent effects on jet evolution during electrospinning of semi-dilute polystyrene solutions," European Polymer Journal, vol. 43, no. 4, pp. 1154-1167, 2007.

[4] C. Lu, P. Chen, J. Li, and Y. Zhang, "Computer simulation of electrospinning. Part I. Effect of solvent in electrospinning," Polymer, vol. 47, no. 3, pp. 915-921, 2006.

[5] L. Wannatong, A. Sirivat, and P. Supaphol, "Effects of solvents on electrospun polymeric fibers: preliminary study on polystyrene," Polymer International, vol. 53, no. 11, pp. 1851-1859, 2004.

[6] T. Uyar and F. Besenbacher, "Electrospinning of uniform polystyrene fibers: the effect of solvent conductivity," Polymer, vol. 49, no. 24, pp. 5336-5343, 2008.

[7] T. Jarusuwannapoom, W. Hongrojjanawiwat, S. Jitjaicham et al., "Effect of solvents on electro-spinnability of polystyrene solutions and morphological appearance of resulting electrospun polystyrene fibers," European Polymer Journal, vol. 41, no. 3, pp. 409-421, 2005.
[8] Q. Yang, Z. Li, Y. Hong et al., "Influence of solvents on the formation of ultrathin uniform poly(vinyl pyrrolidone) nanofibers with electrospinning," Journal of Polymer Science B, vol. 42, no. 20, pp. 3721-3726, 2004.

[9] L. Van der Schueren, B. De Schoenmaker, B. Kalaoglu, and K. De Clerck, "An alternative solvent system for the steady state electrospinning of polycaprolactone," European Polymer Journal, vol. 47, no. 6, pp. 1256-1263, 2011.

[10] W. K. Son, J. H. Youk, T. S. Lee, and W. H. Park, "Electrospinning of ultrafine cellulose acetate fibers: studies of a new solvent system and deacetylation of ultrafine cellulose acetate fibers," Journal of Polymer Science B, vol. 42, no. 1, pp. 5-11, 2004.

[11] S. O. Han, J. H. Youk, K. D. Min, Y. O. Kang, and W. H. Park, "Electrospinning of cellulose acetate nanofibers using a mixed solvent of acetic acid/water: effects of solvent composition on the fiber diameter," Materials Letters, vol. 62, no. 4-5, pp. 759$762,2008$.

[12] S. Tungprapa, T. Puangparn, M. Weerasombut et al., "Electrospun cellulose acetate fibers: effect of solvent system on morphology and fiber diameter," Cellulose, vol. 14, no. 6, pp. 563575, 2007.

[13] Z. Ma, M. Kotaki, and S. Ramakrishna, "Electrospun cellulose nanofiber as affinity membrane," Journal of Membrane Science, vol. 265, no. 1-2, pp. 115-123, 2005.

[14] D. Haas, S. Heinrich, and P. Greil, "Solvent control of cellulose acetate nanofibre felt structure produced by electrospinning," Journal of Materials Science, vol. 45, no. 5, pp. 1299-1306, 2010.

[15] H. Liu and Y.-L. Hsieh, "Ultrafine fibrous cellulose membranes from electrospinning of cellulose acetate," Journal of Polymer Science B, vol. 40, no. 18, pp. 2119-2129, 2002.

[16] J. F. Kadla and R. Korehei, "Effect of hydrophilic and hydrophobic interactions on the rheological behavior and microstructure of a ternary cellulose acetate system," Biomacromolecules, vol. 11, no. 4, pp. 1074-1081, 2010.

[17] J. Burke, Ed., Solubility Parameters: Theory and Application, vol. 3 of The Book and Paper Group Annual, 1984.

[18] C. Hansen, Hansen Solubility Parameters: A User's Handbook, CRC Press, Boca Raton, Fla, USA, 2nd edition, 2007.

[19] M. Karimi, W. Albrecht, M. Heuchel et al., "Determination of water/polymer interaction parameter for membrane-forming systems by sorption measurement and a fitting technique," Journal of Membrane Science, vol. 265, no. 1-2, pp. 1-12, 2005.

[20] A. Vetere, "A simple modification of the Flory-Huggins theory for polymers in non-polar or slightly polar solvents," Fluid Phase Equilibria, vol. 34, no. 1, pp. 21-35, 1987.

[21] B. A. Miller-Chou and J. L. Koenig, "A review of polymer dissolution," Progress in Polymer Science, vol. 28, no. 8, pp. 12231270, 2003.

[22] N. Olaru and L. Olaru, "Electrospinning of cellulose acetate phthalate from different solvent systems," Industrial and Engineering Chemistry Research, vol. 49, no. 4, pp. 1953-1957, 2010.

[23] M. W. Frey, "Electrospinning cellulose and cellulose derivatives," Polymer Reviews, vol. 48, no. 2, pp. 378-391, 2008.

[24] S. Koombhongse, W. Liu, and D. H. Reneker, "Flat polymer ribbons and other shapes by electrospinning," Journal of Polymer Science B, vol. 39, no. 21, pp. 2598-2606, 2001.

[25] A. Celebioglu and T. Uyar, "Electrospun porous cellulose acetate fibers from volatile solvent mixture," Materials Letters, vol. 65, no. 14, pp. 2291-2294, 2011.

[26] C. Appaw, Rheology and microstructure of cellulose acetate in mixed solvent systems [Ph.D. thesis], North Carolina State University, USA, North Carolina, NC, USA, 2004. 
[27] G. C. Rutledge, Y. Li, and S. Fridrikh, "Electrostatic spinning and properties of ultrafine fibers," National Textile Center Annual Report, 2000.

[28] O. Suwantong, P. Opanasopit, U. Ruktanonchai, and P. Supaphol, "Electrospun cellulose acetate fiber mats containing curcumin and release characteristic of the herbal substance," Polymer, vol. 48, no. 26, pp. 7546-7557, 2007.

[29] P. Goswami, R. S. Blackburn, H. M. El-Dessouky, J. Taylor, and P. White, "Effect of sodium hydroxide pre-treatment on the optical and structural properties of lyocell," European Polymer Journal, vol. 45, no. 2, pp. 455-465, 2009.

[30] G. Salihu, P. Goswami, and S. Russell, "Hybrid electrospun nonwovens from chitosan/cellulose acetate," Cellulose, vol. 19, no. 3 , pp. 739-749, 2012.

[31] M. Dabral, L. F. Francis, and L. E. Scriven, "Drying process paths of ternary polymer solution coating," AIChE Journal, vol. 48, no. 1, pp. 25-37, 2002. 

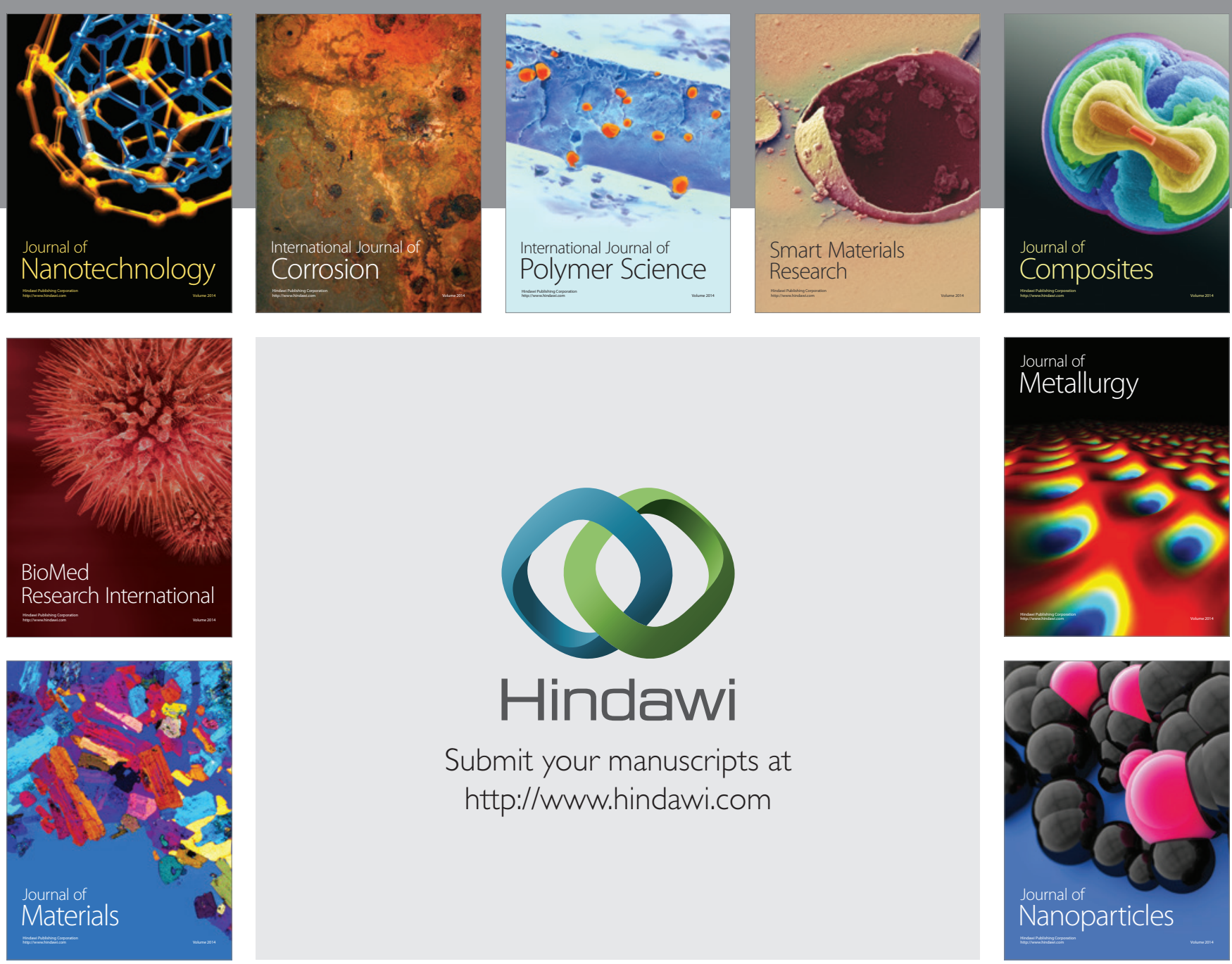

Submit your manuscripts at http://www.hindawi.com
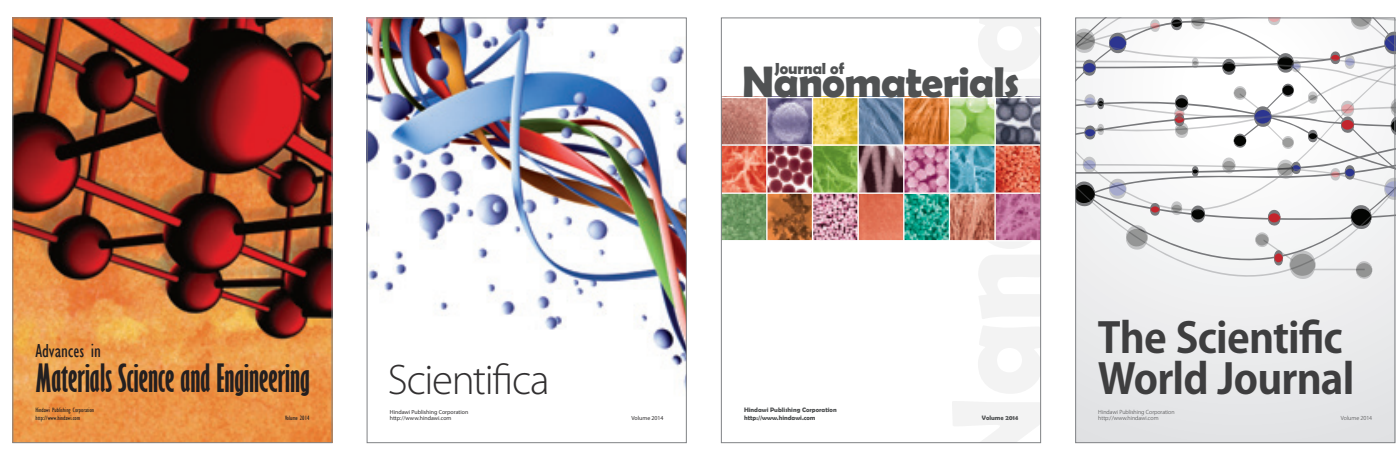

\section{The Scientific World Journal}
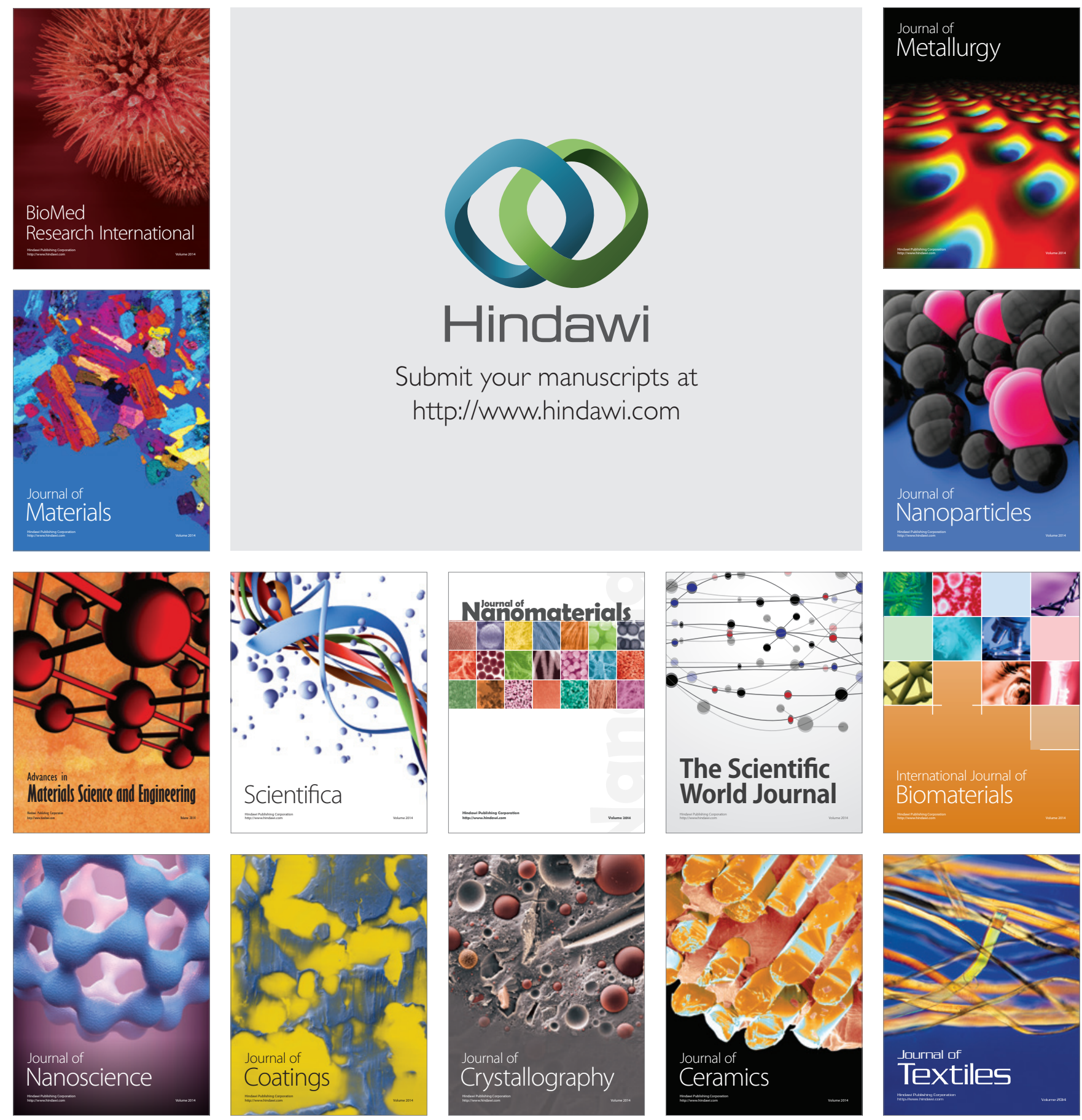